\title{
A LOGÍSTICA REVERSA DAS EMBALAGENS PLÁSTICAS NA NTERPRETAÇÃO DO SUPERIOR TRIBUNAL DE JUSTIÇA À LUZ DO PRINCÍPIO POLUIDOR PA- GADOR
}

\author{
Heron José de Santana Gordilho ${ }^{1}$ \\ Marcia Bittencourt Barbosa Matias ${ }^{2}$
}

Resumo: Este artigo utiliza o método lógico-sistemático para compreender a logística reversa das embalagens plásticas, sob a perspectiva do princípio poluidor pagador. $\mathrm{O}$ artigo questiona se o princípio poluidor pagador é suficiente para impor aos fabricantes de plásticos a implantaçÃo do sistema de logística reversa, tendo em vista o entendimento da $4^{\mathrm{a}}$ Turma do Superior Tribunal de Justiça, que no Recurso Especial 684.753/PR, julgado em 2014, determinou o recolhimento das garrafas plásticas pelo fabricante, independentemente da existência de acordo setorial ou regulamento público.

Palavras-chave: Lei dos Resíduos Sólidos; Externalidades; Desenvolvimento sustentável; Responsabilidade compartilhada; Acordos setoriais.

\section{THE REVERSE LOGISTICS OF PLASTIC PACKAGING IN THE INTERPRETATION OF THE SUPERIOR COURT OF JUSTICE IN THE LIGHT OF THE POLLUTER PAYS PRINCIPLE}

\begin{abstract}
This article uses the logical systematic method to understand the reverse logistics of plastic packaging from the perspective of the polluter pays principle. The article questions whether the polluter pays principle is sufficient to impose on plastic manufacturers the implementation of the reverse logistics system, in view of the understanding of the 4th Panel of the Superior Court of Justice, which in Special Appeal 684.753/PR, judged in 2014, determined the collection of plastic bottles by the manufacturer, regardless of the existence of an industry agreement or public regulation.
\end{abstract}

Keywords: Solid Waste Act; Externalities; Sustainable Development; Shared Responsibility; Sectoral Agreements.

\section{INTRODUÇÃO}

O presente artigo fará uma revisão de jurisprudência sobre o instituto da logística reversa criado pela Lei n.12.305/2010, denominada Lei da Política Nacional de Resíduos Sólidos (LPNRS), que obriga os fornecedores e fabricantes a internalizarem os custos decorrentes das externalidades negativas provocadas pelo descarte inadequado de resíduos sólidos no pósconsumo.

\footnotetext{
${ }^{1}$ Pós-doutor pela Pace University/EUA. Doutor em direito pela UFPE, Professor da UFBA e UCSAL. Promotor de Justiça.

${ }^{2}$ Mestranda do PPGD/UCSAL. Procuradora do Município de Camaçari
} 
A LPNRS obriga os fabricantes, importadores, distribuidores e comerciantes de agrotóxicos de pilhas e baterias; pneus; óleos lubrificantes; lâmpadas fluorescentes; produtos eletrônicos e seus componentes a implementarem a logística reversa; mas não incluí entre eles os produtos de natureza plástica.

$\mathrm{O}$ artigo do $33, \S 1^{\circ}$ e $\S 2$ da LPNRS obriga a implantação da logística reversa às embalagens plásticas mediante acordo setorial com o Poder Público, considerando, prioritariamente, o grau e a extensão do impacto desses resíduos à saúde pública e ao meio ambiente.

Em 2014, todavia, em sede do Recurso Especial n.684.753/PR, a $4^{\mathrm{a}}$ Turma do Superior Tribunal de Justiça(STJ) obrigou a empresa Imperial a promover o recolhimento das embalagens plásticas dos rios, córregos e praças com fundamento no princípio poluidor pagador, tendo em vista que os lucros obtidos pela empresa decorriam do uso desses resíduos.

Utilizando o método lógico-sistemático, este artigo analisará a introdução do princípio poluidor pagador no direito ambiental como forma de corrigir as falhas de mercado decorrentes das externalidades negativas, para em seguida analisar as funções preventiva, repartida e distributiva da logística reversa dos resíduos sólidos introduzidas pela LPNRS.

Por fim, o artigo analisará o entendimento do STJ sobre a possibilidade de se aplicar a logística reversa em relação as embalagens plásticas independentemente da celebração de acordos setoriais.

\section{O DESENVOLVIMENTO SUSTENTÁVEL E A INTERNALIZAÇÃO DAS EX- TERNALIDADES NEGATIVAS ATRAVÉS DO PRINCÍPIO DO POLUIDOR PAGA- DOR}

Os estudos de Pigou em 1920 e de Coese em 1960, se destacavam entre as propostas de solução das externalidades ambientais: enquanto Coese reivindicava que a solução das externalidades deveria ocorrer entre os próprios agentes do mercado através de uma negociação mediada pelo Estado, Pigou acreditava que as externalidades somente seriam evitadas através de intervenções estatais concretas como a imposição de impostos e taxas, o que fez surgir a expressão "taxa pigouviana" (ARAGÃO, 2014, p. 31). 
Antes da década de 60, praticamente não se falava em desenvolvimento sustentável, e a ideia de desenvolvimento sempre esteve relacionada ao conceito de crescimento do PIB (ARAGÃO, 2014, p.44).

O princípio do desenvolvimento sustentável foi cunhado na Conferência das Nações Unidas sobre Meio Ambiente, realizada em Estocolmo em1972(ONU, 1972) e aprimorado na Conferência das Nações Unidas sobre o Meio Ambiente realizada no Rio de Janeiro em 1992 (ONU, 1992), através da adoção da Agenda 21 e da Declaração do Rio.

O desenvolvimento sustentável é o patrimônio transmitido entre gerações para que todos possam satisfazer suas necessidades com qualidade de vida, o que exige que o Estado, a sociedade e as atividades econômicas adotem processos produtivos que permitam a conservação dos recursos através do reaproveitamento e recuperação, mas também pela introdução de novos padrões de consumo (BARBERI, 2014, p.32).

No começo dos anos 70, porém, com a escassez dos bens ambientais e as falhas de mercado decorrentes dos subsídios dados por alguns Estados, a Organização de Cooperação e Desenvolvimento Econômico (OCDE), em uma reunião sobre o uso recursos hídricos, aprovou a Recomendação C(72),128 de 26 de maio de 1972, introduziu o princípio poluidor pagador como um princípio internacional e econômico, destinado a repassar o ônus da poluição aos seus causadores (GORDILHO, PIMENTA, 2018 p. 366).

O princípio poluidor pagador busca corrigir as externalidades negativas decorrentes no processo produtivo, através da "privatização das perdas e socialização dos lucros"(DERANI, 2009, p.141-143).

O princípio do poluidor pagador surge a partir de uma interpretação dos itens 2 e 4 da referida Recomendação, com função meramente preventiva, determinando que o Estado deve repassar ao poluidor os custos das externalidades negativas (GORDILHO, PIMENTA, 2018, p. 366).

O princípio do Poluidor Pagador foi incluído na Declaração do Rio sobre Meio Ambiente e Desenvolvimento através dos princípios 13 e 16, e o contexto nacional, tem sido o 
princípio norteador da responsabilidade civil ambiental no pós-consumo (KOZLOWSKI; ARRAES, [201-?]), nos termos do artigo $4^{\text {o }}$, VII, da Lei n.6938/1991(PNMA). ${ }^{3}$

O combate à poluição visa, através do estabelecimento de instrumentos econômicos e jurídicos, assegurar que as futuras gerações possam desfrutar dos recursos naturais que levaram milhares de anos para a sua formação (AYALA; LEITE, 2000, p.121).

Os bens ambientais são caracterizados por sua utilidade, escassez e imprescindibilidade para a sobrevivência humana, embora os conflitos oriundos da escassez dos bens ambientais não estejam submetidos à lei da economia (GORDILHO; PIMENTA, p. 364).

A economia não regula os bens ambientais porque a essencialidade dos bens ambientais para a sobrevivência humana faz com que eles sejam considerados bens públicos de uso comum do povo (ARAGÃO, 2014, p.23).

A ideia de uso livre dos bens ambientais de interesse comum acaba por produzir externalidades ambientais negativas, que são efeitos externos não controlados pelo sistema de mercado, de modo que custos dessas externalidades não são internalizados pelas empresas como fator de produção (BECHARA, 2017, p.03)

Constituindo o que denominamo-nos de falhas de mercado, as externalidades são comportamento que repercutem que na esfera alheia, e podem ser positivas ou negativas. Exemplo de externalidade positiva é a construção por um empreendimento imobiliário de uma praça público trazendo benefícios a uma comunidade, ao passo que o lançamento de esgoto nos rios e córregos uma externalidade negativa, pois atinge a saúde pública (GORDILHO; PIMENTA, 2018, p.364).

Os prejuízos que os produtos plásticos podem acarretar à natureza, considerando o grande quantidade descartada no meio ambiente e danos à saude humana quando ingeridos são imensos (PARKER, 2020) (SABOIA, 2018).

Constatada a dificuldade de auto-ajuste dos mercados em refletir as demandas ambientais, o PPP, previsto no artigo 4, VII da LPNMA e a logística reversa prevista na LPNRS,

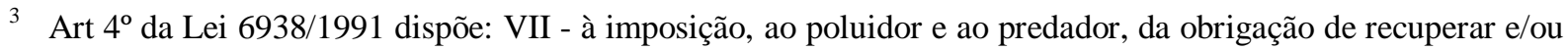
indenizar os danos causados e, ao usuário, da contribuição pela utilização de recursos ambientais com fins econômicos.
} 
almejam atingir o máximo ecológico através de um máximo econômico (DERANI, 1996, p.113-116).

Nesta linha de raciocínio, é preciso que as empresas respeitem os princípios e os processos ecológicos, evitando assim a desarmonia ambiental e suas consequências para os interesses da atual e das futuras gerações.

O Estado, principal destinatário do PPP, tem o dever de estabelecer instrumentos jurídicos que assegurem o repasse dos custos ambientais aos poluidores, pois a atuação livre do mercado tende a maximizar o lucro e favorecer os interesses privados em detrimento do equilíbrio ambiental (MILARÉ, 2016, p.36).

\section{AS FUNÇÕES PREVENTIVA, REPARATIVA E DISTRIBUTIVA DO PRINCÍPIO DO POLUIDOR-PAGADOR}

Apesar de existirem opiniões em contrário, não se pode confundir a função preventiva do poluidor pagador com o princípio da prevenção, nem com o princípio da reparação, ele modo que ambos devem ser considerados sub-princípios do PPP (ARAGÃO, 2014, p. 107111).

O principio da prevenção, em sentido amplo, subdivide-se em prevenção em sentido estrito e precaução, que é a adoção de medidas visando evitar os riscos ambientais decorrentes da incerteza científica.

O PPP também se distingue da responsabilidade civil, pois, o poluidor pagador tem finalidade preventiva e reparadora, ao passo em que, a responsabilidade civil, além da função reparadora, tem também uma função sancionatória.

A função reparadora do PPP tem o condão de distribuir os custos ambientais causados pelo poluidor, evitando que os mesmos sejam assumidos pelo Estado ou pela sociedade, razão pela qual, o princípio do poluidor pagador tem uma vocação distributiva.

A finalidade do PPP não se restringe apenas a cumprir sua vocação distributiva dos custos ambientais entre os poluidores, uma vez que, se assim o fosse, seria permitido ao contaminador pagar pelo direito de poluir, desde que isso lhe fosse economicamente vantajoso. 
Assim, antes de exteriorizar a função de distribuir um ônus negativo para quem deu causa, deve-se entender que a finalidade principal do PPP é preventiva, de modo que, é preciso ficar claro que o PPP não concede o direito de pagar para poluir e sequer tem uma conotação compensatória, se destinando, antes de tudo, a evitar a poluição ambiental. (MILARÉ, 2013, p.198).

A função distributiva transfere o ônus ao poluidor, além de proporcionar a equidade econômica e a justiça social, incentivando condutas a favor do ambiente, já que os produtos, acrescidos dos custos sócio-ambientais terão seus preços elevados (GORDILHO, PIMENTA, 2018, p.374).

Se medidas anti-poluentes forem aplicadas para todos com uniformidade, os produtos e serviços sustentáveis terão preços mais baratos, e essa foi a intenção da criação do princípio do poluidor pagador.

Por intermédio do princípio poluidor-pagador, os custos da prevenção ou reparação dos danos ambientais devem ser transferidos para a atividade econômica, a partir de instrumentos como as taxas, a imposição de medidas tecnológicas, e instrumentos jurídicos como a implementação da logística reversa dos produtos potencialmente poluentes (LIMA, 2015, p.110).

\section{A LOGÍSTICA REVERSA E A RESPONSABILIDADE COMPARTILHADA NA LPNRS}

Transcorridos 20 anos de tramitação no Congresso Nacional da edição da Lei n.12.305/2010, denominada Lei da Política Nacional de Resíduos Sólidos (LPNRS) e do Decreto Federal n.7404 de 2010, poucos avanço têm ocorrido no Brasil para o adequado gerenciamento do resíduos sólidos.

A LPNRS criou novos instrumentos jurídicos tais como os acordos setoriais ${ }^{4} 56$ a responsabilidade compartilhada ${ }^{7}$ e a logística reversa, ${ }^{8}$ além de cunhar novos conceitos como o de ciclo de vida de um produto ${ }^{9}$ (KOZLOWSKI; ARRAES, p.3).

\footnotetext{
${ }^{4}$ No artigo $3^{\circ}$ da Lei 12.305/2020, tem-se o conceito de acordo setorial:
} 
Artigo $3^{\circ}$ Para fins desta Lei, entende-se por:

I - acordo setorial: ato de natureza contratual firmado entre o poder público e fabricantes, importadores, distribuidores ou comerciantes, tendo em vista a implantação da responsabilidade compartilhada pelo ciclo de vida do produto.

5 Art. 19 do decreto 7404/2010 que: Os acordos setoriais são atos de natureza contratual, firmados entre o Poder Público e os fabricantes, importadores, distribuidores ou comerciantes, visando a implantação da responsabilidade compartilhada pelo ciclo de vida do produto."

§ 3o Poderão participar da elaboração dos acordos setoriais representantes do Poder Público, dos fabricantes, importadores, comerciantes e distribuidores dos produtos e embalagens referidos no art. 33 da Lei no 12.305, de 2010, das cooperativas ou outras formas de associações de catadores de materiais recicláveis ou reutilizáveis, das indústrias e entidades dedicadas à reutilização, ao tratamento e à reciclagem de resíduos sólidos, bem como das entidades de representação dos consumidores, entre outros.

${ }^{6}$ Art. 20 do decreto 7404/2010 afirma que:

O procedimento para implantação da logística reversa por meio de acordo setorial poderá ser iniciado pelo Poder Público ou pelos fabricantes, importadores, distribuidores ou comerciantes dos produtos e embalagens referidos no art. 18.

$\S 1$ o Os acordos setoriais iniciados pelo Poder Público serão precedidos de editais de chamamento, conforme procedimento estabelecido nesta Subseção.

$\S 20$ Os acordos setoriais iniciados pelos fabricantes, importadores, distribuidores ou comerciantes serão precedidos da apresentação de proposta formal pelos interessados ao Ministério de Meio Ambiente, contendo os requisitos referidos no art. 23.

${ }^{7}$ Art. 3 PNRS Para os efeitos desta Lei, entende-se por:

XVIII responsabilidade compartilhada pelo ciclo de vida dos produtos: conjunto de atribuições individualizadas e encadeadas dos fabricantes, importadores, distribuidores e comerciantes, dos consumidores e dos titulares dos serviços pulicos de limpeza urbana e de manejo dos resíduos sólidos, para minimizar o volume de resíduos sólidos e rejeitos gerados, bem como para reduzir os impactos causados à saúde humana e à qualidade $\mathrm{d}$ ambiental decorrente do ciclo de vida dos produtos, nos termos da lei.

Art. 30 da PNRS. É instituída a responsabilidade compartilhada pelo ciclo de vida dos produtos, a ser implementada de forma individualizada e encadeada, abrangendo os fabricantes, importadores, distribuidores e comerciantes, os consumidores e os titulares dos serviços públicos de limpeza urbana e de manejo de resíduos sólidos, consoante as atribuições e procedimentos previstos nesta Seção.

${ }^{8}$ Artigo 3 da PNRS Para efeitos desta Lei, entende-se por:

XII - logística reversa: instrumento de desenvolvimento econômico e social caracterizado por um conjunto de ações, procedimentos e meios destinados a viabilizar a coleta e a restituição dos resíduos sólidos ao setor empresarial, para reaproveitamento, em seu ciclo ou em outros ciclos produtivos, ou outra destinação final ambientalmente adequada;

9 Art. $3^{\circ}$ da PNRS Para os efeitos desta Lei, entende-se por: 
Face ao risco da disposição inadequada desses produtos, a estruturação da logística reversa dos produtos plástico e demais produtos constantes no artigo 33 I-VI da lei $12.305 / 2010$ (pneus, produtos eletrônicos, etc. ${ }^{10}$ a LPNRS exige que a responsabilidade pela disposição desses resíduos seja compartilhada entre todos os sujeitos da cadeia produtiva, de produtores a consumidores (KOZLOWSKI et al, 2016, p.1453).

A LPNRS não desconhece o papel do consumidor como poluidor direto, de forma que o artigo $84, \S 2^{\circ}$ e $3^{\circ}$ do Decreto n. $7404 / 2010^{11}$ lhe imputa uma multa em caso de reincidên-

IV- ciclo de vida do produto: série de etapas que envolvem o desenvolvimento do produto, a obtenção de matérias primas e insumos, processo produtivo, o consumo e disposição final.

10 Vejam no artigo 33 da PNRS como ficou disposta a logistica reversa obrigatória de produtos como pneus e dos plásticos:

Art. 33 da PNRS. São obrigados a estruturar e implementar sistemas de logística reversa, mediante retorno dos produtos após o uso pelo consumidor, de forma independente do serviço público de limpeza urbana e de manejo dos resíduos sólidos, os fabricantes, importadores, distribuidores e comerciantes de: (Regulamento)

I - agrotóxicos, seus resíduos e embalagens, assim como outros produtos cuja embalagem, após o uso, constitua resíduo perigoso, observadas as regras de gerenciamento de resíduos perigosos previstas em lei ou regulamento, em normas estabelecidas pelos órgãos do Sisnama, do SNVS e do Suasa, ou em normas técnicas;

II - pilhas e baterias;

III - pneus;

IV - óleos lubrificantes, seus resíduos e embalagens;

V - lâmpadas fluorescentes, de vapor de sódio e mercúrio e de luz mista;

VI - produtos eletrônicos e seus componentes.

$\S 1^{\mathrm{o}} \mathrm{Na}$ forma do disposto em regulamento ou em acordos setoriais e termos de compromisso firmados entre o poder público e o setor empresarial, os sistemas previstos no caput serão estendidos a produtos comercializados em embalagens plásticas, metálicas ou de vidro, e aos demais produtos e embalagens, considerando, prioritariamente, o grau e a extensão do impacto à saúde pública e ao meio ambiente dos resíduos gerados.

$\S 2^{\underline{0}}$ A definição dos produtos e embalagens a que se refere o $\S 1^{\circ}$ considerará a viabilidade técnica e econômica da logística reversa, bem como o grau e a extensão do impacto à saúde pública e ao meio ambiente dos resíduos gerados.

${ }^{11}$ Art. 84 do decreto 7404/2010: O art. 62 do Decreto ${ }^{\circ}$ 6.514, de 22 de julho de 2008, passa a vigorar com a seguinte redação:

"Art. 62.

$\S 2^{\circ}$ Os consumidores que descumprirem as respectivas obrigações previstas nos sistemas de logística reversa e de coleta seletiva estarão sujeitos à penalidade de advertência. 
cia da sanção de advertência por descumprimento das obrigações previstas no sistema de logística reversa.

Estas medidas devem está associadas a campanhas educativas (Art. $8^{\circ}$,VIII da LPNRS e 77 do 7404/2010), uma vez que de nada adianta o fornecedor estruturar o sistema da logística reversa se o consumidor não levar o produto ao ponto de coleta.

Observando-se o disposto no artigo 3, XVIII e 30, VII da LPNRS, a responsabilidade compartilhada é um instituto que estabelece deveres individuais e encadeados em relação ao ciclo de vida do produto, desde a prevenção dos resíduos ao seu gerenciamento, compatibilizando os interesses do empresariado com a sustentabilidade ambiental (MENDES, 2015).

Cada participante do ciclo produtivo do resíduo, individualmente e de forma encadeada, é responsável pelo ciclo de vida do produto, já que a omissão dessas obrigações provoca riscos de degradação do meio ambiente e da saúde pública, sujeitando os seus agentes à responsabilidade civil solidária e objetiva, sem prejuízo das sanções penais ou administrativas (MENDES, 2015, p.69).

Embora ambos os instrumentos visem a promoção da tutela ambiental, o instituto da logística reversa não deve ser confundido com a responsabilidade compartilhada, que é um instituto com regramento próprio associada à responsabilidade civil ambiental, que é solidária e objetiva (MENDES, 2015, p.69).

Ainda que o objetivo da LPNRS não seja disciplinar a responsabilidade civil, que está tratada no artigo $14, \S 1^{\circ}$ da LPNMA $^{12}$, diante da concepção equivocada de que ela trata ape-

$\S 3^{\underline{o}}$ No caso de reincidência no cometimento da infração prevista no $\S 2^{\underline{o}}$, poderá ser aplicada a penalidade de multa, no valor de $\mathrm{R} \$ 50,00$ (cinquenta reais) a $\mathrm{R} \$ 500,00$ (quinhentos reais).

$\S 4^{\circ}$ A multa simples a que se refere o $\S 3^{0}$ pode ser convertida em serviços de preservação, melhoria e recuperação da qualidade do meio ambiente.

$\S 5^{\circ}$ Não estão compreendidas na infração do inciso IX as atividades de deslocamento de material do leito de corpos d'água por meio de dragagem, devidamente licenciado ou aprovado

${ }^{12}$ Art 14 - Sem prejuízo das penalidades definidas pela legislação federal, estadual e municipal, o não cumprimento das medidas necessárias à preservação ou correção dos inconvenientes e danos causados pela degradação da qualidade ambiental sujeitará os transgressores:

$\S 1^{\circ}$ - Sem obstar a aplicação das penalidades previstas neste artigo, é o poluidor obrigado, independentemente da existência de culpa, a indenizar ou reparar os danos causados ao meio ambiente e a terceiros, afetados por sua atividade. O Ministério Público da União e dos Estados terá legitimidade para propor ação de responsabilidade civil e criminal, por danos causados ao meio ambiente. 
nas de aterros sanitários e lixões, a sua implementação tem sido deficiente no Brasil(BENJAMIN, 2020).

A LPNRS instituiu a logística reversa nos artigos $3^{\circ}$, XII ${ }^{13}$ e 33 , obrigando fabricantes, fornecedores e consumidores a participar do retorno dos produtos prejudiciais ao meio ambiente ao ciclo produtivo (VELÁZQUEZ; MARCON, 2017, p.207).

Assim, a responsabilidade compartilhada é o gênero do qual a logística reversa é espécie, já que existem várias formas de responsabilidade compartilhada, tais como a obrigação do fabricante de produzir bens ambientalmente sustentáveis (Art. 31, I da LPNRS) ${ }^{14}$ ou a promoção de acordos setoriais com o poder público sobre produtos não previstos no sistema de logística reversa (Art.31,VI da LPNRS). ${ }^{15}$

Como instrumento de responsabilidade compartilhada previsto nos artigos $3^{\circ}$, XII da LPNRS, a logística reversa consiste em um conjunto de ações e procedimentos realizados pela

13 Artigo 3 da PNRS Para efeitos desta Lei, entende-se por:

XII - logística reversa: instrumento de desenvolvimento econômico e social caracterizado por um conjunto de ações, procedimentos e meios destinados a viabilizar a coleta e a restituição dos resíduos sólidos ao setor empresarial, para reaproveitamento, em seu ciclo ou em outros ciclos produtivos, ou outra destinação final ambientalmente adequada;

${ }^{14}$ Art. 31. Sem prejuízo das obrigações estabelecidas no plano de gerenciamento de resíduos sólidos e com vistas a fortalecer a responsabilidade compartilhada e seus objetivos, os fabricantes, importadores, distribuidores e comerciantes têm responsabilidade que abrange: (grifos, nossos)

I - investimento no desenvolvimento, na fabricação e na colocação no mercado de produtos:

a) que sejam aptos, após o uso pelo consumidor, à reutilização, à reciclagem ou a outra forma de destinação ambientalmente adequada;

15 Art. 31. Sem prejuízo das obrigações estabelecidas no plano de gerenciamento de resíduos sólidos e com vistas a fortalecer a responsabilidade compartilhada e seus objetivos, os fabricantes, importadores, distribuidores e comerciantes têm responsabilidade que abrange:

IV- compromisso de, quando firmado acordos ou termos de compromisso com o Município, participar das ações previstas no plano municipal de gestão integrada de residuos solidos, no caso de produtos ainda não inclusos no sistema de logistica reversa. 
cadeia produtiva para reinserir os resíduos em outros ciclos produtivos até esgotarem todas as possibilidade de aproveitamento (MIRANDA; MAYA, 2015, p.114).

Alguns autores sustentam que esse retorno acarreta um aumento do custo, uma vez que outros processos e procedimentos sob a responsabilidade do fabricante se inserem na fase pós- consumo, de modo que visando reduzir os custos da adoção do sistema de logística reversa, os empresários tendem a produzir bens ambientalmente sustentáveis, nos termos do apontado no artigo 31, I da LPNRS (CIPRIANO, 2020).

Os valores agregados pela criação e implementação da logística reversa podem compelir os empreendedores a reduzir os seus custos através da adoção de novas tecnologias que estabeleçam alternativas sustentáveis (FILHO SILVA, 2012,p.122), seja com o investimento no Eco-design ${ }^{16}$ (MENDES, 2015, p.77), seja com a produção de bens duráveis e materiais menos poluentes e que gerem menos resíduos (MOREIRA, 2020), como a substituição dos sacos plásticos de polietilenos por sacos plásticos de vegetais retornáveis (ARAGÃO, 2020).

A orientação é evitar a geração de resíduos, mas se isso não for possível, deve-se promover a sua reutilização através da reciclagem, e por fim a sua adequada disposição final (MENDES, 2015,p.51).

Iniciativas de circularidade vão desde a reutilização das embalagens retornáveis, como é o caso da Coca-Cola, que no ano de 2018 deixou de colocar no ambiente 1,6 bilhões de garrafas novas (ABRELPE) até o reaproveitamento de fabricantes do meio de eletrônicos, como a HP, que têm transformados equipamentos descartados em matéria-prima para novos produ-

16 O estimulo a fabricação de produtos sustentáveis (ecodesigne) e sua relação com a logística reversa podem serem vistos no artigo 31 da Lei 12.305/10, in verbis:

Art. 31. Sem prejuízo das obrigações estabelecidas no plano de gerenciamento de resíduos sólidos e com vistas a fortalecer a responsabilidade compartilhada e seus objetivos, os fabricantes, importadores, distribuidores e comerciantes têm responsabilidade que abrange:

I - investimento no desenvolvimento, na fabricação e na colocação no mercado de produtos:

a) que sejam aptos, após o uso pelo consumidor, à reutilização, à reciclagem ou a outra forma de destinação ambientalmente adequada;

b) cuja fabricação e uso gerem a menor quantidade de resíduos sólidos possível; 
tos. Além disse, podemos citar o recente compromisso global de mais de 450 organizações para o desenvolvimento de uma economia circular direcionada aos plásticos (SILVA, 2020).

Apesar do sucesso apontado pela ABRELPE em relação a reutilização ou reciclagem, nem sempre este é o melhor caminho a seguir, pois o processo de reutilização de garrafas de vidro faz uso de recursos escassos ou poluentes, tais como água, detergentes e combustíveis fósseis para percorrer grandes distâncias (ARAGÃO, 2009, p.33).

\section{A POSIÇÃO DO STJ SOBRE A OBRIGATORIEDADE DA LOGÍSTICA REVERSA DE RESÍDUOS PLÁSTICOS INDEPENDENTEMENTE DE ACORDOS SETORIAIS}

Aparentemente o artigo 33, I-VI da LPNRS estabeleceu um dano presumido em relação a determinados resíduos, mas quando se trata de embalagens plásticas, a logística reversa estaria condicionada a acordos com o Poder Público, desde que constatada a sua nocividade ao equilíbrio ecológico e à saúde pública.

Não obstante, em 2014, no Recurso Especial 684.753/PR, a $4^{\mathrm{a}}$ Turma do STJ ${ }^{17}$ decidiu, a partir do PPP, que a empresa Imperial tinha a obrigação de recolher as garrafas plásticas

\footnotetext{
${ }^{17}$ RECURSO ESPECIAL No 684.753 - PR (2004/0080082-9)

RELATOR : MINISTRO ANTONIO CARLOS FERREIRA

RECORRENTE : REFRIGERANTES IMPERIAL LTDA

ADVOGADOS : FÁBIO CARRARO E OUTRO (S) TALI BLANCHE E OUTRO (S)

RECORRIDO : HABITAT ASSOCIAÇÃO DE DEFESA E EDUCAÇÃO AMBIENTAL

ADVOGADO : JEAN MAURÍCIO DE SILVA LOBO
}

\section{EMENTA}

DIREITO CIVIL. AÇÃO CIVIL PÚBLICA. ASSOCIAÇÃO DE DEFESA AO MEIO AMBIENTE. GARRAFAS "PET". ABANDONO EM LOGRADOUROS PÚBLICOS. RESPONSABILIDADE PÓS-CONSUMO. DANOS AMBIENTAIS. OBRIGAÇÃO DE FAZER DA RÉ, FABRICANTE DE REFRIGERANTE. 1. Condenada a ré em obrigação de fazer requerida na petição inicial, falta-lhe interesse recursal para se insurgir contra a parte subsequente da condenação, na qual o Tribunal de origem permitiu-lhe, "facultativamente", satisfazer a referida obrigação de fazer de uma outra forma, diversa da postulada na inicial, evidentemente se à própria ré for mais benéfica ou de mais fácil satisfação.

2. Acolhida a pretensão relativa à obrigação de fazer, consubstanciada em campanha publicitária sobre o recolhimento e troca das garrafas "PET", não caracteriza julgamento extra ou ultra petita a definição dos contornos e da forma pela qual a referida obrigação deverá ser cumprida com eficácia, antecipando a solução de um tema que geraria discussões na fase de execução, ou seja, de como plenamente cumprir a campanha publicitária.

3. Ausente o alegado decaimento mínimo na demanda por parte da ré, descabe afastar a condenação nos honorários advocatícios. 
descartadas de maneira inadequada no meio ambiente, tendo em vista a potencialidade lesiva destes resíduos sólidos.

Um argumento a favor da logística reversa obrigatória dos plásticos à luz do artigo 33 I-IV é o de que os produtos mencionado nesse artigo são meramente exemplificativos, de modo que a estruturação do sistema da logística reversa está condicionado tão somente à aferição dos danos que determinados produtos podem causar ao ambiente (BENJAMIM, MAGALHÃES).

A função preventiva do princípio do poluidor pagador exige que a logística reversa seja obrigatória e aplicada para qualquer produto que ao final do seu ciclo de vida possa causar danos ao meio ambiente.

4. Condenando-se a ré apenas em obrigação de fazer, não é possível fixar a verba honorária entre $10 \%$ e $20 \%$ sobre o valor da condenação.

5. Aplica-se a vedação da Súmula 283 do STF por ter a recorrente deixado de impugnar a incidência da Lei n. $7.347 / 1985$, dos arts. $1^{\circ}$ e $4^{\circ}$ da Lei Estadual $n$.

$12.943 / 1999$ e $14, \S 1^{\circ}$, da Lei n. 6.938/1981, com base nos quais o Tribunal de origem concluiu que, "cuidandose aqui da chamada responsabilidade pós-consumo de produtos de alto poder poluente, é mesmo inarredável o envolvimento dos únicos beneficiados economicamente pela degradação ambiental resultante - o fabricante do produto e o seu fornecedor".

6. A interpretação da legislação estadual contida no acórdão não pode ser revista nesta instância especial, a teor da Súmula n. 280 do STF ("por ofensa a direito local não cabe recurso extraordinário").

7. Falta prequestionamento, explícito ou implícito, dos artigos 267, I, 283, 295, parágrafo único, I e II, 333, I, e 396 do CPC, não apreciados nos acórdãos da apelação e dos aclaratórios, cabendo ressaltar que o recurso especial não veicula afronta ao art. 535 do CPC.

8. Sendo incontroversos os fatos da causa e entendendo o Tribunal de origem, com base em normas legais específicas sobre o mérito, haver responsabilidade e culpabilidade por parte da ré, que lucra com o uso das garrafas "PET", caberia à recorrente trazer normais legais igualmente meritórias em seu favor, não servindo para reformar o acórdão recorrido os artigos 267, I, 283, 295, parágrafo único, I e II, 333, I, e 396 do CPC.

9. Recurso especial conhecido em parte e desprovido.

\section{ACÓRDÃo}

Após o voto do relator, conhecendo parcialmente do recurso e negando-lhe provimento, no que foi acompanhado pelos Ministros Marco Buzzi, Luis Felipe Salomão e Maria Isabel Gallotti, e o voto do Ministro Raul Aráujo dando provimento ao recurso, divergindo do relator, a Quarta Turma, por maioria, conheceu parcialmente do recurso e, nesta parte, negou-lhe provimento, nos termos do voto do Sr. Ministro Relator. Vencido o Sr. Ministro Raul Araújo (Presidente).

A Quarta Turma, por maioria, não acolheu a questão de ordem suscitada pelo Ministro Raul Araújo. Os Srs. Ministros Marco Buzzi, Luis Felipe Salomão e Maria Isabel Gallotti votaram com o Sr. Ministro Relator.

Brasília-DF, 04 de fevereiro de 2014 (Data do Julgamento) 
A LPNRS e o Decreto que a regulamenta, demonstram uma falha técnica do legislador que parece confundir os conceitos, já que o acordo setorial é apenas uma das formas de implementação da responsabilidade compartilhada ao lado da logística reversa (KOZLOWSKI; ARRAES, [201-], p.3).

Segundo o Acórdão do STJ:

a) incidência da hipótese normativa do PPP determina a transferência dos custos das externalidades ambientais negativas ao poluidor, uma vez que o dano se operou com a disposição inadequada dos resíduos sólidos. Se o dano ocorre, resta a função reparadora e o tribunal deve aplicá-la;

b) Outros danos poderão advir do descarte inadequado dos resíduos, tendo em vista a continuidade da atividade, já que novas garrafas serão transformadas em resíduos caso o sistema de logística reversa não seja implementado;

c) Além da responsabilidade civil ambiental, a empresa Imperial ,tem a obrigação de estruturar um sistema de logística reversa dos seus resíduos, independente de acordo setorial, com base no artigo 33, I-VI da LPNRS.

Assim, em razão da norma prevista no PPP, embora o artigo 33, I VI da LPNRS não determine expressamente que a estruturação do sistema de logística reversa seja obrigatória em caso de resíduos plásticos, exigindo a celebração de acordos setoriais, sempre que for constatada a lesividade ambiental dos resíduos plásticos, o STJ entende que o sistema de logística reversa deve ser adotado.

Seja como for, a responsabilidade civil pós-consumo dos fabricantes pode provocar uma mudança comportamental na atividade econômica, que preventivamente pode reduzir os custos ambientais e econômicos investindo em produtos que proporcionem um menor impacto ambiental (MOREIRA, 2020).

O STJ entendeu que o rol da atividades sujeitas ao sistema de logística reversa é meramente exemplificativo, e que a continuidade da atividade torna possível o advento de novos danos ambientais causados pelo acondicionamento irregular das garrafas plásticas, de modo que a função preventiva do PPP deve prevalecer, independentemente da existência de acordos setoriais ou regulamentos do Poder Publico. 


\section{CONCLUSÃO}

Como visto, o poluidor pagador, tendo em vista o acesso livre aos recursos naturais e sendo comum a propriedade, determina que o Estado crie normas jurídicas ou econômicas que garantam a internalização dos custos sociais para prevenção ou reparação de danos ambientais pelo poluidor, garantindo, assim, a redução da ocorrência das externalidades negativas no meio ambiente.

Não obstante, embora o artigo 33, I VI da LPNRS não determine expressamente que a estruturação do sistema de logística reversa seja obrigatória em caso de resíduos plásticos, exigindo a celebração de acordos setoriais para tal fim, o STJ entende que sempre que for constatado que descarte de um determinado resíduo sólido provoque danos ambientais, o sistema de logística reversa deveres obrigatoriamente adotado.

Desse modo, a vocação distributiva do PPP pode ser percebida no sistema da logística reversa, que ao atribuir os custos da poluição para aquele que lhe deu causa, poderá provocar uma mudança de postura dos fabricantes e fornecedores de serviços para que os mesmo passem a privilegiar produtos e serviços ambientalmente sustentáveis.

\section{REFERÊNCIAS}

ARAGÃO, Alexandra O princípio poluidor pagador: pedra angular da politica comunitário do ambiente. Instituto do Planeta Verde: São Paulo, 2014.

ARAGÃO, Alexandra. 10 anos da Política Nacional de resíduos sólidos. In: Seminário virtual do instituto o direito por um planeta verde, 2, 2020, Online.

ARAGÃO, Alexandra. Direito Administrativo dos Resíduos. In: OTERO, Paulo.; GONÇALVES, Pedro Costa. Tratado de Direito Administrativo Especial. Coimbra: Almedina, 2009. p.11-158.

AYALA, Patrick de Araújo; LEITE, José Rubens Morato. A transdisciplinaridade do direito ambiental e sua equidade intergeracional. Revista Sequência, v. 21, n. 41 p.113-136, 2000.

BARBERI, José Carlos. Desenvolvimento e ambiente as estratégias de mudanças e agenda 21. 15. ed. São Paulo: Vozes, 2014. 
BECHARA, Erika. Princípio do poluidor pagador. 2020. Disponível em: https://enciclopediajuridica.pucsp.br/verbete/334/edicao-1/principio-do-poluidor-pagador. Acesso: 10 jan. 2021.

BENJAMIN, Antonio Herman; MAGALHÃES, Assusete.10 anos da Política Nacional de resíduos sólidos. In: Seminário virtual do instituto o direito por um planeta verde, 2, 2020, Online.

BRASIL. [Constituição (1988)]. Constituição da República Federativa do Brasil. Brasília, DF: Presidência da República, [1988]. Disponível em:

http://www.planalto.gov.br/ccivil_03/constituicao/constituicao.htm. Acesso em: 10 jun. 2020.

BRASIL. Decreto n 7404, de 23 de dezembro de 2010. Dispõe Regulamenta a Lei

no 12.305, de 2 de agosto de 2010, que institui a Política Nacional de Resíduos Sólidos, cria o Comitê Interministerial da Política Nacional de Resíduos Sólidos e o Comitê Orientador para a Implantação dos Sistemas de Logística Reversa, e dá outras providências. Brasília, DF: Presidência da República, [2010b]. Disponível em:

http://www.planalto.gov.br/ccivil_03/_ato2007-2010/2010/Decreto/D7404.htm. Acesso em: 10 jun. 2020.

BRASIL. Lei no 12.305, de 2 de agosto de 2010. Institui a Política Nacional de Resíduos Sólidos; altera a Lei no 9.605, de 12 de fevereiro de 1998; e dá outras providências. Brasília, DF: Presidência da República, [2010a]. Disponível em: http://www.planalto.gov.br/ccivil_03/_ato2007-2010/2010/lei/112305.htm. Acesso em: 10. jun. 2020.

BRASIL. Lei no 6.938, de 31 de agosto de 1981. Dispõe sobre a Política Nacional do Meio Ambiente, seus fins e mecanismos de formulação e aplicação, e dá outras providências. Diário Oficial da União, Brasília, 2 set.1981. Disponível em:

http://www.planalto.gov.br/ccivil 03/LEIS/L6938.htm. Acesso em: 10. jun. 2020

BRASIL. Lei no 6.938, de 31 de agosto de 1981. Dispõe sobre a Política Nacional do Meio Ambiente, seus fins e mecanismos de formulação e aplicação, e dá outras providências. Brasília, DF: Presidência da República, [1981]. Disponível em: http://www.planalto.gov.br/ccivil_03/LEIS/L6938.htm. Acesso em: 10. jun. 2020

BRASIL, Superior Tribunal de Justiça. Recurso especial n. 684.753 - PR, Recorrente: Refrigerante Imperial LTDA, Recorrido:Habitat Associação de Defesa e Educação Ambiental. Relator: Ministro Antonio Carlos Ferreira, Jul.04.fev.2014. Disponível em: https://www.jusbrasil.com.br/diarios/documentos/134004819/recurso-especial-n-684753-prdo-stj. Acesso em: 10 jul. 2020

CIPRIANO, Tasso Alexandre.10 anos da Política Nacional de resíduos sólidos. In: Seminário virtual do instituto o direito por um planeta verde, 2, 2020, Online.

DERANI, Cristiane. Direito Ambiental Econômico. São Paulo: Max limonadi,1996.

DERANI, Cristiane. Direito Ambiental Econômico. 3 ed. São Paulo: Saraiva, 2009 
FILHO SILVA, Carlos Costa. O princípio poluidor pagador: Da eficiência econômica à realização da justiça. Revista de Direito da Cidade, v.4, n.2, p. 111- 128, 2012.

GORDILHO, Heron José de Santana; PIMENTA, Paulo Roberto Lyrio. Fins do princípio do poluidor-pagador. Revista Brasileira de Direito, v. 14, n. 1, p. 361-379, 2018.

KOZLOWSKI, Luzia Hilda et al. Responsabilidade Ambiental pos consumo à luz do princípio poluidor pagador: uma análise do nível de implementação da responsabilidade compartilhada pelo ciclo de vida dos produtos prevista na política nacional de resíduos sólidos. Revista Direito da Cidade, v.8, n. 4, p. 1442- 1467, 2016.

KOZLOWSKI, Luzia Hilda; ARRAES, Ricardo Velloso Arraes. Orientador: Danielle de Andrade Moreira. $\mathbf{O}$ princípio do poluidor pagador aplicado à responsabilidade ambiental pós consumo: implementação incipiente da responsabilidade compartilhada pelo ciclo de vida dos produtos. [201-] Disponível em: http://www.puc-

rio.br/pibic/relatorio_resumo2016/relatorios_pdf/ccs/DIR/DIR-

Hilda\%20e\%20Ricardo\%20Arraes.pdf. Acesso em: 20 jun. 2020.

LIMA, Murilo Carvalho Miranda; FERREIRA, Fernando Joaquim. A logística reversa como instrumento de efetividade do Princípio Poluidor Pagador na redução dos impactos ambientais. Londrina: Scientia Iuris, 2015.

MENDES, Mucio Amado João. A responsabilidade compartilhada pelo ciclo de vida dos produtos na cadeia eletrônicos. Dissertação. (Mestrado em Direito) - Faculdade de Direito, Universidade de São Paulo. São Paulo, 2015.

MILARÉ, Édis. Direito do Ambiente. 8 ed. São Paulo: Revista dos Tribunais, 2013.

MILARÉ, Edis. Relação Jurídica à danosidade ambiental: Contribuição para o delineamento de um microssistema de responsabilidade. Tese. (Doutorado em Direito) - Faculdade de Direito, Programa de Estudos Pós-Graduados em Direito, Pontifícia Universidade Católica de São Paulo, São Paulo, 2016.

MIRANDA, Murilo Carvalho; MAYA; Fernando Joaquim Ferreira. A Logística reversa como instrumento de efetividade do Princípio Poluidor Pagador na redução dos impactos ambientais. Scientia Iuris, v. 19, n. 02, p.101-126, 2015.

MOREIRA, Daniele de Andrade. 10 anos da Política Nacional de resíduos sólidos. In: Seminário virtual do instituto o direito por um planeta verde, 2, 2020, Online.

ONU. Declaração da Conferência das Nações Unidas sobre o Meio Ambiente Humano 1972. Disponível em:

https://www.apambiente.pt/_zdata/Politicas/DesenvolvimentoSustentavel/1972_Declaracao_E stocolmo.pdf. Acesso em: 12 jun. 2020.

ONU. Declaração do Rio sobre meio ambiente e desenvolvimento. 1992. Disponível em: https://cetesb.sp.gov.br/proclima/wp-content/uploads/sites/36/2013/12/declaracao_rio_ma.pdf Acesso em: 16 jun. 2020. 
PARKER, Laura. Poluição por plasticos é um problema grave- mas ainda não é tarde para solucioná-lo. 2020. Disponivel na internet:

https://www.nationalgeographicbrasil.com/ciencia/2020/10/poluicao-por-plastico-e-umproblema-grave-mas-ainda-nao-e-tarde-demais. Acesso em : 15. Ago. 2021

SABOIA, Elaine. Plásticos nos oceanos colocam em risco a saúde humana e a fauna. 2018. Disponível em: http://noticias.unisanta.br/campus/graves-riscos-a-saude-humana-emortandade-da-fauna-marinha-inspiram-o-movimento-internacional-break-from-plastic-nasemana-do-meio-ambiente. Acesso em: 20 jun. 2020.

SILVA, Cleide. Porque mais empresas apostam em economia circular: Alternativa ao modelo de produção, consumo e desencarte, conceito prevê a transformação de resíduos em novas matérias-primas na indústria. 2020. Disponível em:

https://www.estadao.com.br/infograficos/economia,por-que-mais-empresas-apostam-naeconomia-circular,1117170. Acesso em: 12 out. 2020.

VELÁZQUEZ, Victor Hugo Tejerina; MARCON, Victor Trevilin Benatti. Aspecto relevante da logística reversa na política nacional de resíduos sólidos. Revista Direito Ambiental e sociedade, v. 7, n. 3, p. 201-229, 2017. 